\title{
ENDOMETRIOMA DE PARED ABDOMINAL. UNA CAUSA DE DOLOR ABDOMINAL RECURRENTE EN MUJER DE EDAD FÉRTIL*
}

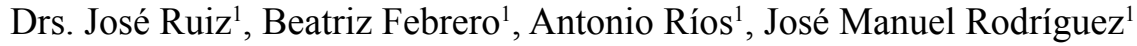 \\ 1 Servicio de Cirugía General y del Aparato Digestivo. Hospital Clínico Universitario "Virgen de la Arrixaca". \\ Murcia, España.
}

\section{Abdominal wall endometrioma. A recurrent abdominal pain cause in a women of childbearing age}

Mujer de 42 años que consultó por dolor abdominal recurrente en fosa ilíaca derecha durante el ciclo menstrual de 6 meses de evolución. Entre sus antecedentes destacaban 2 cesáreas. En la exploración física se apreciaba una masa dolorosa a la palpación profunda en fosa ilíaca derecha. La analítica era normal.

En la ecografía (Figura 1) se evidenció una lesión subcutánea, adyacente al tercio inferior del músculo recto, de 4,5 x $4 \mathrm{~cm}$, hipoecogénica, mal definida y sin vascularización significativa. La tomografía computarizada (Figura 2) confirmó la localización descrita en la ecografía. Se realizó resección completa de la tumoración (Figura 3). El estudio histológico confirmó que se trataba de un endometrioma.

El endometrioma de pared abdominal se asocia a la cicatriz de cesárea en un 57\% y a histerectomía en un $11 \%$. Se produce en mujeres con una edad media de 31,4 años. Se presenta como masa abdominal en

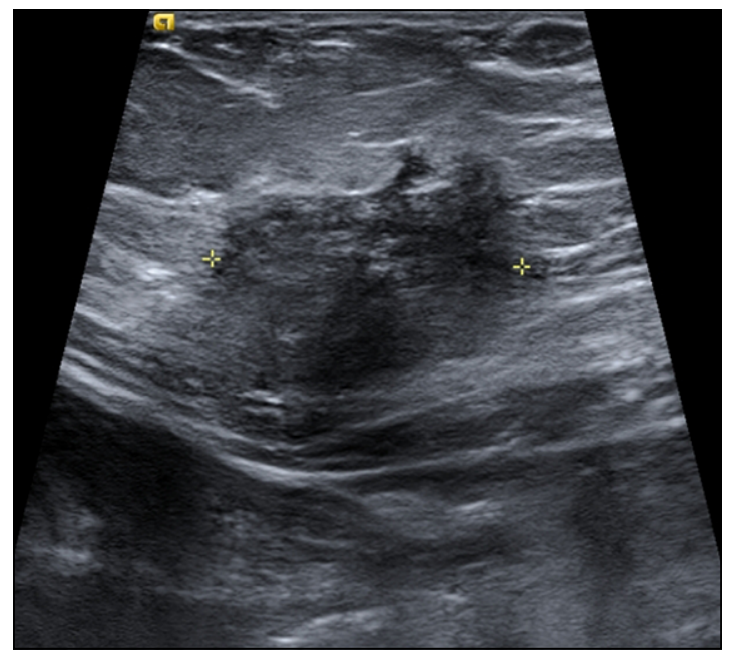

Figura 1. Ecografía que muestra la masa. un $96 \%$, con dolor en un $87 \%$, y en un $57 \%$ síntomas cíclicos. Suele presentarse 3,6 años después

*Recibido el 12 de junio de 2015 y aceptado para publicación el 21 de julio de 2015.

Conflictos de interés: Ninguno

Correspondencia: Dr. José Ruiz josrp@hotmail.es 


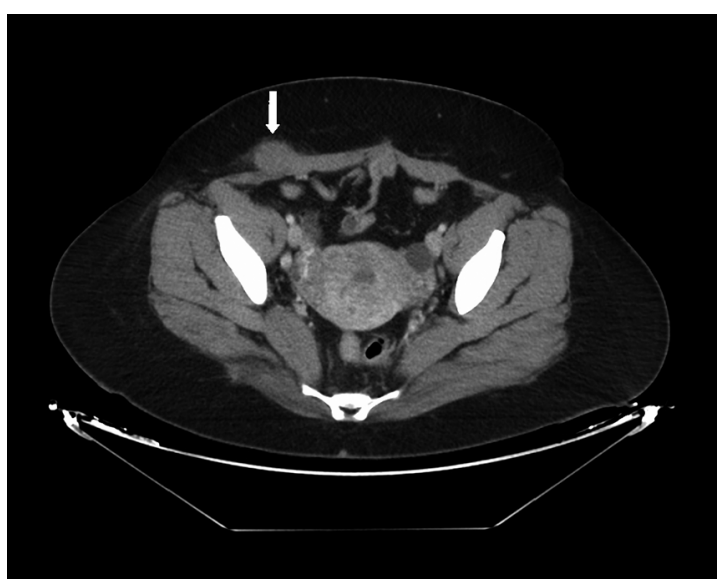

Figura 2. TC que confirma la lesión.

de la cirugía uterina. El tratamiento quirúrgico es curativo en más del $95 \%$, pero recidivan el $4,3 \%{ }^{1}$.

Ante una masa abdominal dolorosa en mujer en edad fértil con antecedentes de cesárea, se debe descartar un endometrioma de pared abdominal.

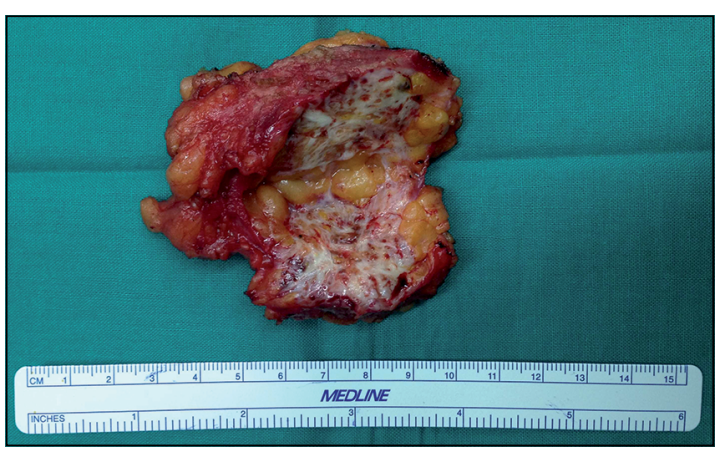

Figura 3. Pieza quirúrgica.

\section{Referencias}

1. Horton JD, Dezee KJ, Ahnfeldt EP, Wagner M. Abdominal wall endometriosis: a surgeon's perspective and review of 445 cases. Am J Surg. 2008;196:207-12. 